\title{
Anti-TNF therapy for juvenile idiopathic arthritis-related uveitis
}

This article was published in the following Dove Press journal:

Drug Design, Development and Therapy

24 March 2014

Number of times this article has been viewed

\author{
Francesco Semeraro' \\ Barbara Arcidiacono ${ }^{2}$ \\ Giuseppe Nascimbeni' \\ Martina Angi' \\ Barbara Parolini² \\ Ciro Costagliola ${ }^{3}$ \\ 'Eye Clinic, Department of \\ Neurological Sciences and Vision, \\ University of Brescia, Brescia, Italy; \\ ${ }^{2}$ Department of Ophthalmology, \\ S. Anna Hospital, Brescia, Italy; ${ }^{3}$ Eye \\ Clinic, Department of Health \\ Sciences, University of Molise, \\ Campobasso, Italy
}

Correspondence: Barbara Arcidiacono Oculistica, Istituto Clinico Sant'Anna, Via del Franzone 3I, 25I00, Brescia, Italy Email b.arcidiacono@libero.it

\begin{abstract}
Juvenile idiopathic arthritis-related uveitis is the most common type of uveitis in childhood and one of the main causes of visual impairment in children. The introduction of biological treatment has widened the range of therapeutic options for children with uveitis refractory to standard nonbiologic immunosuppressants. Data from clinical trials suggest that both adalimumab and infliximab have demonstrated effectiveness and safety in open-label studies, although no large, randomized, controlled trials have been reported so far. The role of etanercept in treating juvenile idiopathic arthritis-related uveitis is not yet well defined. In our experience, anti-tumor necrosis factor therapy has been shown to be more effective than steroids and/or methotrexate in treating uveitis. Up to now, tumor necrosis factor blocking compounds have been reserved for the treatment of the most severe cases of refractory uveitis, and larger prospective clinical trials are required in order to better assess the safety of these new compounds.
\end{abstract}

Keywords: adalimumab, etanercept, infliximab

\section{Introduction}

Juvenile idiopathic arthritis (JIA) is a term that describes a heterogeneous group of disorders of unknown etiology and constitutes the main connective tissue disease in childhood and adolescence. It encompasses several disease categories, each one of which has distinct methods of presentation, clinical signs, and symptoms, and, in some cases, genetic background, occurring in children younger than 16 years. The cause of disease is still poorly understood but seems to be related to both genetic and environmental factors, which result in the heterogeneity of the illness. It represents a major cause of functional disability and ocular pathology in childhood. ${ }^{1}$ JIA-related uveitis accounts for the majority of identifiable causes of childhood-onset uveitis in North America and Europe, representing between $20 \%$ and $40 \%$ of most pediatric uveitis cohorts. ${ }^{2,3}$ It is the most severe complication of JIA and is observed in $30 \%$ of patients with antinuclear antibody (ANA)-positive titers. ${ }^{4}$ It typically involves the anterior chamber, is asymptomatic and bilateral, and follows an indolent chronic course, with $60 \%-80 \%$ of cases lasting over 3 months. Although atypical, granulomatous inflammation and involvement of the posterior segment of the eye have also been described., 5 JIA-related uveitis may develop before, at the same time as, or after the arthritis onset. ${ }^{7}$ Risk factors for the development of uveitis in children with JIA are early onset of the disease, oligoarticular subtype, ANA-positive titers, female sex, specific human leukocyte antigen markers, and short duration of disease. ${ }^{8,9}$ It is associated with a high rate of complications, ${ }^{5,10}$ including posterior synechiae, cataract, glaucoma, and band keratopathy, causing visual impairment in the affected children. Moreover, in many 
cases, the significant ocular morbidity carried by this disease lasts well into adulthood.

Treatment of JIA-related uveitis remains a significant clinical challenge. The course is often persistent, with periods of improvement and flares, leading to significant morbidity. Initial therapy starts with topical corticosteroids and mydriatics, using systemic medications in the event of poor clinical response or if side effects of the topical agents are experienced. Systemic therapy typically includes corticosteroids, methotrexate, mycophenolate mofetil, azathioprine, and chlorambucil. There is increasing recognition that anti-tumor necrosis factor (TNF)- $\alpha$ agents hold promise in the treatment of JIA-associated uveitis, bringing an important addition to the pharmacological options for treatment of this particular form of uveitis.

\section{TNF- $\alpha$}

Human TNF- $\alpha$ is an inflammatory cytokine with numerous functions, translated as a $26 \mathrm{kDa}$ protein. ${ }^{11}$ Newly synthesized pro-TNF- $\alpha$, expressed on the plasma membrane, is cleaved in the extracellular domain thanks to the action of matrix metalloproteinases, releasing a mature soluble $17 \mathrm{kDa}$ protein with a length of 157 amino acids. Trimerization is required for both forms to develop biological activity. The cell-associated form is thought to be responsible for juxtacrine signaling secondary to cell-to-cell contact. ${ }^{12}$ The specific functions of cell-associated and secreted TNF- $\alpha$ are not yet fully understood, although it is clear that the two forms have both overlapping and distinct biological activities. TNF- $\alpha$-converting enzyme (TACE, also known as ADAM-17) is the primary enzyme producing a secreted form of TNF- $\alpha$ by processing cell-associated TNF- $\alpha .{ }^{13}$ TACE is an adamalysin, a member of a class of membrane-associated enzymes endowed with both disintegrin and matrix metalloproteinase domains. These enzymes are essential for the processing of several membraneassociated proteins, including TNF- $\alpha$, Fas ligand, the TNF receptors (TNFRs), and the epidermal growth factor receptor. The biological responses to TNF- $\alpha$ are mediated by two receptors: type 1 (TNFR1, also known as p60, p55, CD120a) and type 2 (TNFR2, also known as p80, p75, CD120b). Both receptors are transmembrane glycoproteins with multiple cysteine-rich repeats in the extracellular N-terminal domains. Although their extracellular domains share structural and functional homology, their intracellular domains are distinct, and transduce their signals through both overlapping and distinct pathways. TNFR1 differs from TNFR2 because it contains a death domain absent in TNFR2. The death domain is a sequence of approximately 70 amino acids necessary for
TNF- $\alpha$ to trigger cellular apoptosis. It provides a docking site for a number of accessory proteins, including Fas-associated death-domain-containing protein, TNFR1-associated deathdomain-containing protein, and TNFR-associated factor 2. TNFR1-associated death-domain-containing protein and TNFR-associated factor 2 provide the branching points for the proapoptotic and inflammatory signaling pathways that are characteristic of TNFR1. Under physiological conditions, signaling through TNFR1 seems to be primarily responsible for the proinflammatory and shock-producing properties of TNF- $\alpha$. In contrast, other biological responses to TNF- $\alpha$ seem to be dependent on signaling through both receptors. All nucleated cells express TNFRs, although their distribution varies with cell type. TNFR1 is expressed constitutively on most cell types, whereas expression of TNFR2 can be induced. In addition, TNFR2 is restricted to certain cell types and can discriminate TNF- $\alpha$ from different species. ${ }^{14}$ The receptors differ significantly in their binding affinities for homotrimeric TNF- $\alpha$. In fact, binding of homotrimeric TNF- $\alpha$ to TNFR1 is thought to be essentially irreversible, while binding to TNFR2 is associated with both rapid on and off kinetics. ${ }^{15}$ TNF- $\alpha$ signaling through TNFR2 seems to have a dual action in T-cells. In the absence of TNFR1 signaling, TNF- $\alpha$ promotes the proliferation of naïve T-cells through the actions of TNFR217. Moreover, despite the absence of a death domain, TNFR2 induces apoptosis in activated CD8+ T-cells independent of TNFR1 signaling. ${ }^{16,17}$ Both TNFRs on the cell surface can be cleaved by members of the matrix metalloproteinase family in response to inflammatory signals. Most organs of the body are affected by TNF- $\alpha$, and the cytokine exerts various biological functions that will contribute towards the modulation of local inflammation in a cell-to-cell contact manner, as well as in a cell-type-specific fashion; however, many of the functions of TNF- $\alpha$ are not yet fully understood. The cytokine possesses both growth-stimulating and growth-inhibitory properties, and it appears to have self-regulatory features as well. For example, TNF- $\alpha$ induces neutrophil proliferation during inflammation, but it also induces neutrophil apoptosis upon binding to the TNF-R55 receptor. ${ }^{18}$ The cytokine is produced by several types of cells, but especially by macrophage. Tracey and Cerami ${ }^{19}$ suggested two reasons for TNF- $\alpha$ to be continuously expressed. First, the low levels of the cytokine may aid in maintaining homeostasis by regulating the body's circadian rhythm. Furthermore, low levels of TNF- $\alpha$ promote the remodeling or replacement of injured and senescent tissue by stimulating fibroblast growth. Other beneficial functions of TNF- $\alpha$ include its role in the immune response to bacterial and certain fungal, viral, and parasitic invasions, as well as 
its role in the necrosis of specific tumors. Second, it acts as a key intermediary in the local inflammatory immune response. TNF- $\alpha$ is an acute-phase protein that initiates a cascade of cytokines and increases vascular permeability, recruiting macrophages and neutrophils to the site of infection. TNF- $\alpha$ secreted by macrophages promotes blood clotting, which helps contain the infection.

Although TNF- $\alpha$ is required for normal immune responses, as described above, its chronic overexpression has severe pathological consequences.

\section{Role of TNF- $\alpha$ in JIA-related uveitis}

A controlled study ${ }^{20}$ on the profile of cytokines in patients suffering from uveitis associated with JIA has shown that the aqueous humor samples of patients with uveitis, compared to controls, had increased levels of certain cytokines, such as interleukin (IL)-2, IL-6, IL-10, IL-13, IL-18, interferon- $\gamma$, and TNF- $\alpha$. The levels of IL- 8 and IL-10 were lower in patients with uveitis in the quiescent phase and in those treated with methotrexate, compared to the patients with active uveitis or without treatment. There were no significant differences between patients who used topical and/or systemic steroids and patients who did not. The authors found, in children with uveitis, an increase in the aqueous humor levels of cytokines, chemokines, and soluble adhesion factors, even in the absence of apparent inflammation. Another controlled study ${ }^{21}$ demonstrated high levels of TNF- $\alpha$ in the aqueous humor and serum of patients with recurrent uveitis, as compared to healthy controls. Such levels were higher in the serum than in the aqueous humor. Some authors have suggested that TNF- $\alpha$ participates actively in the pathogenesis of uveitis, although it seems to have a more important role systemically rather than locally. In animal models, it has been demonstrated that experimentally induced autoimmune uveoretinitis is CD4+ Th1 dependent. ${ }^{22}$ A chronically activated T-cell produces, directly and indirectly, not only TNF- $\alpha$, but also IL-1, IL-6, chemokines such as IL-8, inhibiting factors of macrophages, and metalloproteinases. A rise in tissue concentrations of TNF induces increased responsiveness of T-cells and macrophage activation, both events eventually causing tissue damage. These effects can be suppressed by anti-TNF agents.

\section{Use of anti-TNF- $\alpha$ agents for the treatment of JIA-related uveitis}

Anti-TNF- $\alpha$ agents used for the treatment of inflammatory ocular diseases include monoclonal antibodies directed against TNF- $\alpha$, such as infliximab and adalimumab, and fusion proteins obtained by recombinant DNA technology, like etanercept, a soluble TNF- $\alpha$ receptor with greater binding affinity than TNFR1 and TNFR2. Two other TNF- $\alpha$ inhibitors, golimumab and certolizumab pegol, have just recently been brought into the market, hence there is still limited evidence of their use in the treatment of uveitis. ${ }^{23}$

The molecular structure, posology, side effects, and clinical application of each of these agents in respect of JIA-related uveitis are presented below.

\section{Infliximab}

Infliximab was the first commercially available agent for blocking TNF- $\alpha$. It is a $149 \mathrm{kDa}$ chimeric immunoglobulin (Ig) G1 monoclonal antibody, composed of the constant regions of the human $\mathrm{IgGl} \mathrm{K}$ spliced to the murine variable antigen-binding region of a high-affinity human anti-TNF- $\alpha$ antibody. ${ }^{24}$ Infliximab (Remicade; Janssen Biotech, Inc, Horsham, PA, USA) neutralizes the functional activity of TNF- $\alpha$ by blocking its binding to the receptors, ${ }^{25}$ but it does not neutralize a related cytokine, TNF- $\beta .{ }^{26}$ Infliximab is administered as intravenous infusions up to $10 \mathrm{mg} / \mathrm{kg}$ at 4- to 8-week intervals after loading doses at baseline and at 2 weeks. Adverse effects include development of an infusion reaction; opportunistic infections, including latent tuberculosis; malignancies; lupus-like reactions; and rise of autoantibodies and transaminases. Patients must be screened for hepatitis $\mathrm{B}$ and $\mathrm{C}$ as well as tuberculosis with chest $\mathrm{X}$-ray and the tuberculin skin test. ${ }^{27}$ Infliximab is not approved by the US Food and Drug Administration (FDA) for use in JIA patients; however, it is approved for treating pediatric Crohn's disease in patients of 6 years or older, hence it has been used off-label also for JIA-related uveitis.

The efficacy of infliximab for treating uveitis has been extensively reviewed in adult patients suffering from Behçet disease and ankylosing spondylitis, in whom infliximab has proved to be a valid therapeutic option controlling ocular inflammation in most cases. Publications regarding the use of infliximab for treating JIA-related uveitis are certainly fewer and, with some exceptions, include smaller numbers of patients. In 2003, Mangge et $\mathrm{al}^{28}$ suggested a beneficial effect of infliximab in controlling severe uveitis in a pediatric patient with prolonged polyarticular JIA. Later, Richards et $\mathrm{al}^{29}$ stated that, using infliximab, it was possible to reduce the dose or withdraw some glaucoma, steroid, or other immunomodulatory drugs. In their experience, infliximab proved to achieve better uveitis control and a simpler drug regimen, as well as possibly improving safety of surgical intervention. Three retrospective series of pediatric patients with uveitis, treated with infliximab, showed good results, with control of 
ocular inflammation in all cases and without serious adverse events. ${ }^{30-32}$ Beneficial results of infliximab infusions for uveitis were also reported in a prospective study investigating its effects on refractory childhood uveitis. ${ }^{33,34}$

\section{Etanercept}

Etanercept (Enbrel; Amgen Inc, Thousand Oaks, CA, USA) is a recombinant fusion protein combining two human soluble p75 TNF receptors with an Fc domain of human IgG1 which binds both TNF- $\alpha$ and TNF- $\beta$. It is a large and complex molecule, with a molecular weight of $150 \mathrm{kDa}$. It functions as a soluble receptor for TNF- $\alpha$ and possesses a binding affinity higher than that of other soluble receptors. Due to its long half-life of 98 to 300 hours, it is administered with a subcutaneous weekly injection at a dose of $0.8 \mathrm{mg} / \mathrm{kg}$. Common side effects include a local reaction at the injection site, which usually does not require special care. Other undesired effects as a consequence of etanercept's anti-inflammatory and immunosuppressive activity, which interferes with the host's defense against infections, include respiratory infections, reactivation of tuberculosis, and sepsis. FDA approved etanercept for the treatment of moderate-to-severe polyarticular-course JIA in patients of 2 years of age and older. ${ }^{35}$

A few studies have evaluated etanercept in the treatment of uveitis in children. A retrospective report of three JIA patients, a randomized, placebo-controlled trial $(n=12)$, and a questionnaire-based survey failed to show a treatment effect. ${ }^{36-38}$ On the contrary, a mild improvement of ocular inflammation during etanercept therapy was found in $60 \%$ of ten children for up to 3 months, ${ }^{39}$ and in $40 \%$ for up to 1 year, ${ }^{40}$ Other research reported that etanercept was not superior to placebo in preventing uveitic relapses in previously controlled patients attempting to taper methotrexate use. ${ }^{41}$

\section{Adalimumab}

Adalimumab (Humira; Abbott Laboratories, Abbott Park, IL, USA), is a recombinant IgG1 monoclonal antibody containing only human peptide sequences targeting TNF- $\alpha$ and is classified as a fully humanized antibody. Adalimumab has a highly specific affinity to TNF- $\alpha$, providing a tight binding to soluble and cell-surface TNF- $\alpha$ and blocking the interaction with its receptors. ${ }^{26}$ Being a highly specific agent targeting TNF- $\alpha$, adalimumab does not inhibit the lymphotoxin TNF- $\beta$, which is produced by lymphocytes and which activates a variety of cellular signals. It is administered subcutaneously at the dosage of $40 \mathrm{mg}$ every 1 to 2 weeks. Since adalimumab is fully humanized, there is less risk of developing autoantibodies and severe allergic reactions; otherwise, the side effect profile is similar to that of infliximab. ${ }^{42}$ In February 2008, adalimumab received FDA approval for the treatment of moderate-to-severe active polyarticular JIA in patients aged 4 years and older. ${ }^{43}$

So far, adalimumab has generally shown a good safety and efficacy profile. Two small case series reported that it induced regression of ocular inflammation in almost $80 \%$ of cases. ${ }^{44,45}$ A retrospective observational study of 20 patients with JIA and chronic uveitis treated with adalimumab reported that 7/20 (35\%) patients had an improvement, $1 / 20$ (5\%) worsened, and 12/20 (60\%) did not show a significant change in the activity of uveitis. The mean number of recurrences/year decreased from 1.9 to 1.4 during adalimumab treatment. Serious adverse events or side effects were not significant, so that adalimumab can be considered a potential treatment option in JIA-associated uveitis, even in patients nonresponsive to previous other anti-TNF therapy. Nevertheless, seven patients in this study discontinued adalimumab during the follow-up: six because of inefficacy and one because of inactive uveitis. ${ }^{46}$ A prospective observational study of 26 Greek children with JIA demonstrated that adalimumab was safe and efficacious during the study period in the majority of patients, controlling recurrent uveitis and radiological progression of disease. ${ }^{47}$ More recently, adalimumab was used in 94 patients with JIA to treat active arthritis and/or active associated uveitis. At the end of the study, uveitis was under control in two-thirds of 54 patients $(31 \%$ did not need any local treatment and $35 \%$ used only one to two corticosteroid drops per day), while one-third had active uveitis (at least three corticosteroid drops per day). According to the Standardization of Uveitis Nomenclature (SUN) criteria, adalimumab treatment for uveitis showed improvement (a two-fold decrease in uveitis activity) in $28 \%$ of patients, with a moderate response in 16 patients, no change in a further 16 patients, and worsening (a two-fold increase in uveitis activity) in $13 \%$ of patients. The overall proportion of patients with active arthritis decreased. At the beginning of the study, $69 \%$ of patients with uveitis had more than two active joints, and at the end of the study only $27 \%$ had active joint disease. In 27 patients with JIA without uveitis on adalimumab, the number of active joints decreased from $93 \%$ to $59 \%$. Systemic corticosteroid treatment could be stopped in $22 \%$ of patients with uveitis and in $11 \%$ of those without uveitis. Most of the patients had received methotrexate, other immunosuppressive therapy, or other biological drugs before initiating adalimumab. ${ }^{48}$ 
Some comparisons between different TNF- $\alpha$ blockers have been performed, suggesting that infliximab causes better clinical responses than etanercept. ${ }^{49,50}$ In 2011, Simonini et $a l^{51}$ directly compared adalimumab and infliximab in a prospective multicenter cohort study of childhood noninfectious chronic uveitis. The authors suggest that, even if limited to a relatively small group (16 patients, 12 of whom were affected by JIA-related uveitis), over 3 years of treatment, adalimumab is more effective than infliximab in maintaining remission of chronic childhood uveitis.

\section{Golimumab}

Golimumab is a completely humanized monoclonal anti-TNF antibody for subcutaneous administration at the dose of 50 $\mathrm{mg}$ once per month. It binds both soluble and membranebound forms of TNF- $\alpha .{ }^{52}$ In preclinical studies, golimumab was shown to have a high affinity for TNF and neutralized TNF effectively. ${ }^{53}$ It is the subject of studies in and is approved for the treatment of rheumatoid arthritis, psoriatic arthritis, and adult ankylosing spondylitis, while a controlled multicenter trial in JIA is still ongoing. ${ }^{54}$ The first report on the use of golimumab in uveitis included an adult patient with JIArelated uveitis who failed other TNF-inhibitor therapies and responded to golimumab. ${ }^{55}$ Recently, William et al ${ }^{56}$ published a small retrospective case series of three patients affected by JIA-related uveitis treated with golimumab, reporting good results, thus concluding that golimumab appears to be safe and provides an alternative treatment in refractory JIA uveitis, even for patients who have not responded to other TNF inhibitors.

\section{Other anti-TNF- $\alpha$ agents}

Certolizumab pegol is a PEGylated Fab fragment of a humanized anti-TNF antibody. The PEGylation of the antibody delays the elimination and thus provides a longer half-life. It was tested in Phase III trials in Crohn's disease and in rheumatoid arthritis. ${ }^{57,58}$ Certolizumab pegol does not possess an Fc-region. Therefore, cell-mediated cytotoxicity is not possible. This could possibly result in a decreased risk for infectious diseases compared with full TNF- $\alpha$ antibodies. To the best of our knowledge, it has not yet been used for the treatment of uveitis.

A new topical TNF blocker for topical use is under development for the treatment of anterior uveitis (ESBA105; NCT00823173). ${ }^{59}$ Topical administration seems to avoid systemic side effects, complications, and inconveniences during application. Its efficacy, however, has not yet been evaluated. ${ }^{60}$

\section{Our experience}

We have used anti-TNF- $\alpha$ agents for treating 12 patients, the majority of whom were female (four males, eight females). Their mean age was 9.7 years, ranging from 2 to 17 years old. According to the literature, nine patients out of $12(75 \%)$ were found positive for ANA (antinuclear antibodies), confirming ANA positivity as a risk factor for uveitis development. The mean interval between the diagnosis of JIA and uveitis was 4 months; in one patient, uveitis preceded the onset of JIA. Moreover, all of them were suffering from oligoarticular JIA, the subtype known to be associated with ocular disease. The patients' uveitis proved to be refractory to topical therapy and second-line agents, being, in our case, corticosteroids and methotrexate. Nine patients received subcutaneous injections of adalimumab at the dose of $24 \mathrm{mg} / \mathrm{m}^{2}$ every other week with a maximum of $40 \mathrm{mg}$ every 2 weeks. Three patients who would not have been compliant with adalimumab, received intravenous infliximab at the dose of $5 \mathrm{mg} / \mathrm{kg}$ at baseline, after 2 and 6 weeks, and then every 6 to 8 weeks. Before starting therapy with anti-TNF agents, all patients underwent chest $\mathrm{X}$-ray, full blood count, and Mantoux test, which proved to be negative in all cases. During the treatment, patients underwent routine assessment consisting of a physical examination, laboratory evaluation with full blood count and inflammation parameters, and kidney and liver function test - every 30 to 45 days for those receiving adalimumab and before each infliximab infusion for the others. All patients underwent ophthalmological evaluation with slitlamp biomicroscopy assessing cells and flare every 8 to 12 weeks. The mean follow-up time was 22 months (standard deviation 15.5 months), ranging from 1 to 42 months.

The efficacy of anti-TNF agents as compared to standard treatment, represented in our case by systemic prednisone and methotrexate, was evaluated on the basis of two main outcome measures: the incidence of uveitis relapses and the occurrence of new complications. The number of relapses was significantly lower $(P<0.001$, Student's $t$-test $)$, a mean of 0.3 relapses for patients during the observational period using anti-TNF therapy, compared to the number of relapses during standard treatment, represented by a mean of 5.25 relapses per patient treated with steroids and methotrexate or methotrexate alone (Figure 1). When comparing the length of disease-free intervals during standard and anti-TNF therapy, Mantel-Cox test (logrank test; $\left.\chi^{2}=13.24 ; P<0.001\right)$ proved a higher survival probability, as in absence of disease, during anti-TNF treatment (Figure 2). Considering that complications, such as synechiae, cataract, 


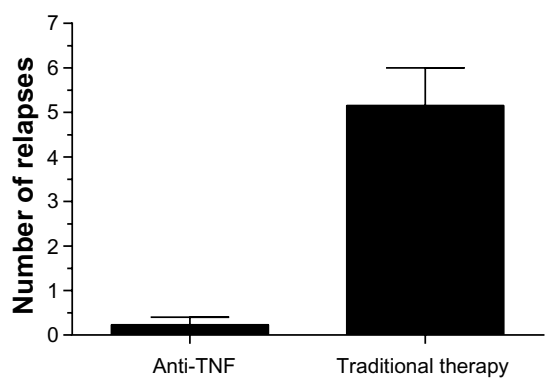

Figure I Patients treated with tumor necrosis factor (TNF)-blocking therapy show a significantly lower number of relapses than those receiving methotrexate and/or steroids (traditional therapy).

glaucoma, band keratopathy, and macular edema, are related to the number of uveitis episodes, it is not surprising that their occurrence was also lower during the follow-up time when using TNF blockers. The most frequent type of complication in our case series were synechiae, followed by cataract formation, band keratopathy, and glaucoma, glaucoma affecting only one patient (Figure 3).

\section{Discussion}

JIA-related uveitis is a chronic disorder, the course of which is characterized by the alternation of periods of relative quiescence with periods of exacerbations, that tend to result in a higher incidence of complications such as cataracts, glaucoma, band keratopathy, and cystoid macular edema, which, in turn, may cause severe visual loss. Therefore, the primary therapeutic goal is to completely eradicate the active intraocular inflammation and the secondary one is to minimize and possibly eliminate the use of topical steroids, the use of which may also cause long-term complications. At present, there are no encoded therapeutic protocols that help in establishing an optimal

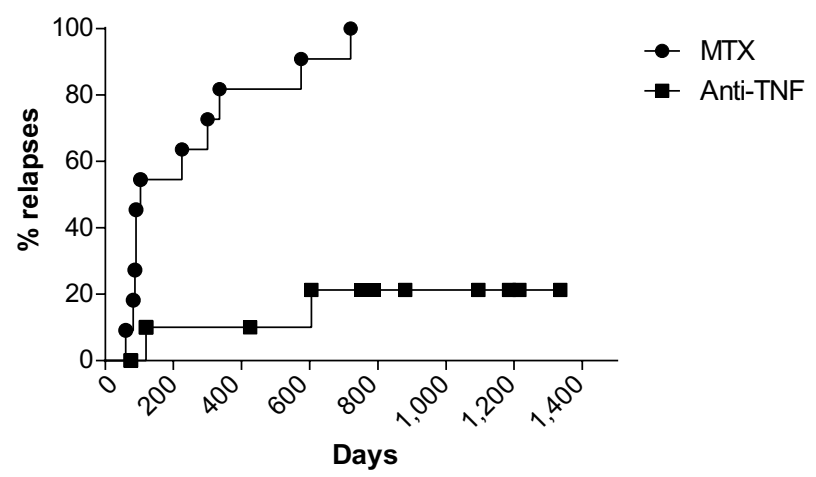

Figure 2 Survival curves representing, on the x-axis, the time (in days) to the first uveitis relapse, with the $y$-axis representing the percentage of relapses.

Note: The slope of the MTX curve demonstrates how the survival rate is lower as the patients experience more relapses $(P<0.00 \mathrm{I})$.

Abbreviations: MTX, methotrexate; TNF, tumor necrosis factor.

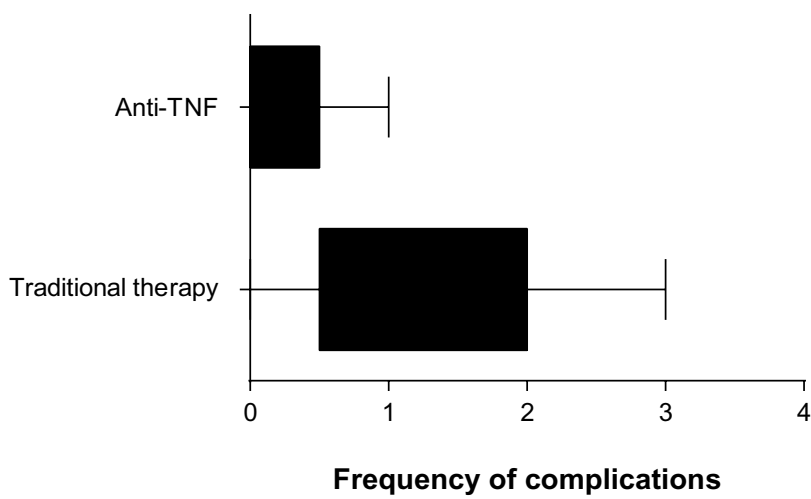

Figure 3 Complication frequency using traditional therapy and with anti-tumor necrosis factor (TNF) agents.

Notes: The majority of patients undergoing traditional therapy, in our case steroids and/or methotrexate, presented a higher frequency of complications (cataract, synechiae, band keratopathy, glaucoma, and macular edema). Lower values resulted in the anti-TNF sample, in which one patient developed synechiae.

treatment for this type of uveitis. Anti-TNF agents have revolutionized the treatment of JIA, as they achieve better control of the disease than previously possible with all other disease-modifying anti-rheumatic drugs. The studies conducted so far, including ours, are in favor of the efficacy of treatment, efficacy that is well supported by the results: the percentages of remission of uveitis patients vary between $40 \%$ and $80 \%$. It is important to emphasize that biological agents are not, as yet, an alternative to conventional therapy, and that their use should be considered only in patients with the most severe and refractory forms of uveitis. The latter are constituted by uveitis with a real risk of developing complications that may cause irreversible visual impairment or by cases that the need a prolonged steroid or immunosuppressive therapy to control the disease. Furthermore, since the number of patients reported to date is still relatively limited, more studies are needed to define more precisely the toxicity profile of the various compounds and, at the same time, to determine whether these therapies can be administered for long times without risk in pediatric patients. TNF-blocking agents allow us to gain better control of the disease, but the main problem is in understanding if and when it is appropriate to discontinue their administration. Clinicians must, in fact, always take account of the possibility that their prolonged use may result in the appearance of significant side effects; knowing that patients suffering from JIA are already, per se, more at risk of developing leukemia and lymphomas makes their use even more challenging. Last but certainly not least, we need to be aware of the high costs of these therapies. This makes necessary, at the time of prescription, an accurate assessment of the cost/benefit ratio. 


\section{Conclusion}

So far, JIA-related uveitis remains one of the main causes of visual impairment in children. Therapy of uveitis typically follows a stepladder approach, beginning with topical corticosteroid drops and mydriatics, with a move to systemic immunosuppressive drugs in case of poor clinical response. Anti-TNF agents bring an important addition to the treatment options for childhood uveitis, in particular adalimumab and infliximab rather than etanercept, the results of which, in the management of JIA-related uveitis, are controversial: some reports even relate the development of uveitis during etanercept therapy in adult patients. ${ }^{61-63}$ Although TNF blockade has beneficial effects in JIA-related uveitis, lack of evidence from randomized controlled studies limits the understanding of when to start therapy, which agent to choose, and how long to continue treatment. In addition, high cost and potential side effects of these drugs have limited their use to uveitis refractory to traditional immunosuppression. Anti-TNF compounds require long-term data to assess their safety, and more prospective, large comparative studies are needed to optimize the treatment of this disease.

\section{Disclosure}

The authors report no conflicts of interest in this work.

\section{References}

1. Kump LI, Cervantes-Castañeda RA, Androudi SN, Foster CS. Analysis of pediatric uveitis cases at a tertiary referral center. Ophthalmology. 2005;112(7):1287-1292.

2. Rabinovich CE. Use of tumor necrosis factor inhibitors in uveitis. Curr Opin Rheumatol. 2007;19:482-486.

3. Holland GN. A reconsideration of anterior chamber flare and its clinical relevance for children with chronic anterior uveitis (an American Ophthalmological Society thesis). Trans Am Ophthalmol Soc. 2007;105: 344-364.

4. Ravelli A, Felici E, Magni-Manzoni S, et al. Patients with antinuclear antibody-positive juvenile idiopathic arthritis constitute a homogeneous subgroup irrespective of the course of joint disease. Arthritis Rheum. 2005;52(3):826-832.

5. Marvillet I, Terrada C, Quartier P, Quoc EB, Bodaghi B, Prieur AM. Ocular threat in juvenile idiopathic arthritis. Joint Bone Spine. 2009;76: 383-388.

6. Keenan JD, Tessler HH, Goldstein DA. Granulomatous inflammation in juvenile idiopathic arthritis-associated uveitis. J AAPOS. 2008;12(6) 546-550.

7. Arnason JA, Bell CL. Juvenile rheumatoid arthritis: current concepts and practice. J Pediatr Ophthalmol Strabismus. 1995;32(6):383-385.

8. SouthwoodTR, Ryder CA. Ophthalmological screening in juvenile arthritis: should the frequency of screening be based on the risk of developing chronic iridocyclitis? Br J Rheumatol. 1992;31(9):633-634.

9. Chen CS, Roberton D, Hammerton ME. Juvenile arthritis-associated uveitis: visual outcomes and prognosis. Can J Ophthalmol. 2004;39(6): 614-620.

10. Heinz C, Mingels A, Goebel C, Fuchsluger T, Heiligenhaus A. Chronic uveitis in children with and without juvenile idiopathic arthritis: differences in patient characteristics and clinical course. J Rheumatol. 2008;35:1403-1407.
11. Perez C, Albert I, DeFay K, Zachariades N, Gooding L, Kriegler M. A nonsecretable cell surface mutant of tumor necrosis factor (TNF) kills by cell-to cell contact. Cell. 1990;63:251-258.

12. Kriegler M, Perez C, DeFay K, Albert I, Lu SD. A novel form of TNF/ cachectin is a cell surface cytotoxic transmembrane protein: ramifications for the complex physiology of TNF. Cell. 1988;53:45-53.

13. Moss ML, Jin SL, Milla ME, et al. Cloning of a disintegrin metalloproteinase that processes precursor tumour-necrosis factor-alpha. Nature. 1997;385:733-736.

14. Baud V, Karin M. Signal transduction by tumor necrosis factor and its relatives. Trends Cell Biol. 2001;11(9):372-377.

15. Grell M, Wajant H, Zimmermann G, Scheurich P. The type 1 receptor (CD120a) is the high-affinity receptor for soluble tumor necrosis factor. Proc Natl Acad Sci U S A. 1998;95:570-575.

16. Alexander-Miller MA, Derby MA, Sarin, A, Henkart PA, Berzofsky JA. Supraoptimal peptide-major histocompatibility complex causes a decrease in bc1-2 levels and allows tumor necrosis factor alpha receptor II-mediated apoptosis of cytotoxic T lymphocytes. J Exp Med. 1998;188:1391-1399.

17. Zheng L, Fisher G, Miller RE, Peschon J, Lynch DH, Lenardo MJ. Induction of apoptosis in mature $\mathrm{T}$ cells by tumour necrosis factor. Nature. 1995;377:348-351.

18. Murray J, Barbara J, Dunkley SA, et al. Regulation of neutrophil apoptosis by tumor necrosis factor-alpha: requirements for TNFR55 and TNFR75 for induction of apoptosis in vitro. Blood. 1997;90(7): 2772-2783.

19. Tracey KJ, Cerami A. Metabolic responses to cachectin/TNF. A brief review. Ann N Y Acad Sci. 1990;587:325-331.

20. Sijssens KM, Rijkers GT, Rothova A, Stilma JS, Schellekens PA, de Boer JH. Cytokines, chemokines and soluble adhesion molecules in aqueous humor of children with uveitis. Exp Eye Res. 2007;85: $443-449$.

21. Santos Lacomba M, Marcos Martín C, Gallardo Galera JM, et al. Aqueous humor and serum tumor necrosis factor-alpha in clinical uveitis. Ophthalmic Res. 2001;33:251-255.

22. Dick AD, Forrester JV, Liversidge J, Cope AP. The role of tumour necrosis factor (TNF-alpha) in experimental autoimmune uveoretinitis (EAU). Prog Retin Eye Res. 2004;23:617-637.

23. Sfikakis PP. The first decade of biologic TNF antagonists in clinical practice: lessons learned, unresolved issues and future directions. Curr Dir Autoimmun. 2010;11:180-210.

24. Knight DM, Trinh H, Le J, et al. Construction and initial characterization of a mouse-human chimeric anti-TNF antibody. Mol Immunol. 1993;30:1443-1453.

25. Scallon BJ, Moore MA, Trinh H, Knight DM, Ghrayeb J. Chimeric anti-TNF-alpha monoclonal antibody cA2 binds recombinant transmembrane TNF-alpha and activates immune effector functions. Cytokine. 1995;7:251-259.

26. Tracey D, Klareskog L, Sasso EH, Salfeld JG, Tak PP. Tumor necrosis factor antagonist mechanisms of action: a comprehensive review. Pharmacol Ther. 2008;117(2):244-279.

27. Furst DE, Keystone EC, Fleischmann R, et al. Updated consensus statement on biological agents for the treatment of rheumatic diseases, 2009. Ann Rheum Dis. 2010;69 Suppl 1:i2-i29.

28. Mangge H, Heinzl B, Grubbauer HM, El-Shabrawi Y, Schauenstein K. Therapeutic experience with infliximab in a patient with polyarticular juvenile idiopathic arthritis and uveitis. Rheumatol Int. 2003;23(5): 258-261.

29. Richards JC, Tay-Kearney ML, Murray K, Manners P. Infliximab for juvenile idiopathic arthritis-associated uveitis. Clin Experiment Ophthalmol. 2005;33(5):461-468.

30. Rajaraman RT, Kimura Y, Li S, Haines K, Chu DS. Retrospective case review of pediatric patients with uveitis treated with infliximab. Ophthalmology. 2006;113(2):308-314.

31. Tugal-Tutkun I, Ayranci O, Kasapcopur O, Kir N. Retrospective analysis of children with uveitis treated with infliximab. J AAPOS. 2008;12(6):611-613. 
32. Sharma SM, Ramanan AV, Riley P, Dick AD. Use of infliximab in juvenile onset rheumatological disease-associated refractory uveitis: efficacy in joint and ocular disease. Ann Rheum Dis. 2007;66:840-841.

33. Kahn P, Weiss M, Imundo LF, Levy DM. Favorable response to high-dose infliximab for refractory childhood uveitis. Ophthalmology. 2006;113(5):860-864. e2.

34. Zannin ME, Birolo C, Gerloni VM, et al. Safety and efficacy of infliximab and adalimumab for refractory uveitis in juvenile idiopathic arthritis: 1-year followup data from the Italian Registry. $J$ Rheumatol. 2013;40(1):74-79.

35. Medication Guide: ENBREL ${ }^{\circledR}$ (en-brel) (Etanercept). Thousand Oaks, CA: Immunex Corporation; 2008. Available from: http://www. accessdata.fda.gov/drugsatfda_docs/label/2008/103795s5359lbl.pdf. Accessed May 26, 2010.

36. Smith JA, Thompson DJ, Whitcup SM, et al. A randomized, placebocontrolled, double-masked clinical trial of etanercept for the treatment of uveitis associated with juvenile idiopathic arthritis. Arthritis Rheum. 2005;53:18-23.

37. Smith JR, Levinson RD, Holland GN, et al. Differential efficacy of tumor necrosis factor inhibition in the management of inflammatory eye disease and associated rheumatic disease. Arthritis Rheum. 2001;45:252-257.

38. Schmeling H, Horneff G. Etanercept and uveitis in patients with juvenile idiopathic arthritis. Rheumatology (Oxford). 2005;44:1008-1011.

39. Reiff A, Takei S, Sadeghi S, et al. Etanercept therapy in children with treatment-resistant uveitis. Arthritis Rheum. 2001;44:1411-1415.

40. Reiff A. Long-term outcome of etanercept therapy in children with treatment refractory uveitis. Arthritis Rheum. 2003;48:2079-2080.

41. Foster CS, Tufail F, Waheed NK, et al. Efficacy of etanercept in preventing relapse of uveitis controlled by methotrexate. Arch Ophthalmol. 2003;121:437-440.

42. Jap A, Chee SP. Immunosuppressive therapy for ocular diseases. Curr Opin Ophthalmol. 2008;19(6):535-540.

43. [Humira approval letter for juvenile idiopathic arthritis]. 2008. Available from: http://www.accessdata.fda.gov/drugsatfda_docs/ appletter/2008/125057s114ltr.pdf. Accessed May 26, 2010.

44. Biester S, Deuter C, Michels H, et al. Adalimumab in the therapy of uveitis in childhood. Br J Ophthalmol. 2007;91:319-324.

45. Vazquez-Cobian LB, Flynn T, Lehman TJ. Adalimumab therapy for childhood uveitis. J Pediatr. 2006;149:572-575.

46. Tynjälä $\mathrm{P}$, Kotaniemi $\mathrm{K}$, Lindahl $\mathrm{P}$, et al. Adalimumab in juvenile idiopathic arthritis-associated chronic anterior uveitis. Rheumatology (Oxford). 2008;47(3):339-344.

47. Trachana M, Pratsidou-Gertsi P, Pardalos G, Kozeis N, Badouraki M, Kanakoudi-Tsakalidou F. Safety and efficacy of adalimumab treatment in Greek children with juvenile idiopathic arthritis. Scand J Rheumatol. 2011;40(2):101-107.

48. Kotaniemi K, Säilä H, Kautiainen H. Long-term efficacy of adalimumab in the treatment of uveitis associated with juvenile idiopathic arthritis. Clin Ophthalmol. 2011;5:1425-1429.

49. Saurenmann RK, Levin AV, Rose JB, et al. Tumour necrosis factor alpha inhibitors in the treatment of childhood uveitis. Rheumatology (Oxford). 2006;45(8):982-989.
50. Tynjälä $\mathrm{P}$, Lindahl $\mathrm{P}$, Honkanen $\mathrm{V}$, Lahdenne $\mathrm{P}$, Kotaniemi K. Infliximab and etanercept in the treatment of chronic uveitis associated with refractory juvenile idiopathic arthritis. Ann Rheum Dis. 2007;66(4): $548-550$.

51. Simonini G, Taddio A, Cattalini M, et al. Prevention of flare recurrences in childhood-refractory chronic uveitis: an open-label comparative study of adalimumab versus infliximab. Arthritis Care Res (Hoboken). 2011;63:612-618

52. Kay J, Matteson EL, Dasgupta B, et al. Golimumab in patients with active rheumatoid arthritis despite treatment with methotrexate: a randomized, double-blind, placebo-controlled, dose-ranging study. Arthritis Rheum. 2008;58:964-975.

53. Shealy D, Cai A, Staquet K, et al. Characterization of golimumab (CNTO 148), a novel fully human monoclonal antibody specific for TNF- alpha. MAbs. 2010;2(4):428-439.

54. Janssen Research and Development, LLC. A study of the safety and efficacy of CNTO 148 (golimumab) in children with juvenile idiopathic arthritis (JIA) and multiple joint involvement who have poor response to methotrexate (GO KIDS) Available from: http://clinicaltrials.gov/ ct2/show/NCT01230827. NLM identifier: NCT01230827. Accessed January 9, 2014.

55. Cordero-Coma M, Salom D, Díaz-Llopis M, López-Prats MJ, Calleja S. Golimumab for uveitis. Ophthalmology. 2011;118(9):1892. e3-e4.

56. William M, Faez S, Papaliodis GN, Lobo AM. Golimumab for the treatment of refractory juvenile idiopathic arthritis-associated uveitis. J Ophthalmic Inflamm Infect. 2012;2(4):231-233.

57. Choy EH, Hazleman B, Smith M, et al. Efficacy of a novel PEGylated humanized anti-TNF fragment (CDP870) in patients with rheumatoid arthritis: a Phase II double-blinded, randomized, dose-escalating trial. Rheumatology (Oxford). 2002;41(10):1133-1137.

58. Sandborn WJ, Feagan BG, Stoinov S, et al; PRECISE 1 Study Investigators. Certolizumab pegol for the treatment of Crohn's disease. N Engl J Med. 2007;357(3):228-238.

59. ESBATech AG. Exploratory Study on Topical ESBA105 in Acute Anterior Uveitis. Available from: http://clinicaltrials.gov/show/ NCT00823173. NLM identifier: NCT00823173. Accessed January 9, 2014.

60. Heiligenhaus A, Thurau S, Hennig M, Grajewski RS, Wildner G. Anti-inflammatory treatment of uveitis with biologicals: new treatment options that reflect pathogenetic knowledge of the disease. Graefes Arch Clin Exp Ophthalmol. 2011;248(11):1531-1551.

61. Kakkassery V, Mergler S, Pleyer U. Anti-TNF-alpha treatment: a possible promoter in endogenous uveitis? observational report on six patients: occurrence of uveitis following etanercept treatment. Curr Eye Res. 2010;35:751-756.

62. Reddy AR, Backhouse OC. Does etanercept induce uveitis? $\mathrm{Br} J$ Ophthalmol. 2003;87(7):925.

63. Taban M, Dupps WJ, Mandell B, Perez VL. Etanercept (enbrel)-associated inflammatory eye disease: case report and review of the literature. Ocul Immunol Inflamm. 2006;14(3):145-150.
Drug Design, Development and Therapy

\section{Publish your work in this journal}

Drug Design, Development and Therapy is an international, peerreviewed open-access journal that spans the spectrum of drug design and development through to clinical applications. Clinical outcomes, patient safety, and programs for the development and effective, safe, and sustained use of medicines are a feature of the journal, which

\section{Dovepress}

has also been accepted for indexing on PubMed Central. The manuscript management system is completely online and includes a very quick and fair peer-review system, which is all easy to use. Visit $\mathrm{http}: / /$ www.dovepress.com/testimonials.php to read real quotes from published authors. 